\title{
Dynamic resolution of functionally related gene sets in response to acute heat stress
}

\author{
Joseph D Szustakowski ${ }^{1}$, Penelope A Kosinski ${ }^{2}$, Christine A Marrese ${ }^{2}$, Jee- \\ Hyung Lee ${ }^{2}$, Stephen J Elliman ${ }^{2}$, Nanguneri Nirmala ${ }^{1}$ and Daniel M Kemp*2
}

\author{
Address: ${ }^{1}$ Developmental and Molecular Pathways, Novartis Institutes for BioMedical Research, Cambridge, Massachusetts, USA and ${ }^{2}$ Diabetes \& \\ Metabolism Disease Area, Novartis Institutes for BioMedical Research, Cambridge, Massachusetts, USA \\ Email: Joseph D Szustakowski - joseph.szustakowski@novartis.com; Penelope A Kosinski - penny.kosinski@novartis.com; \\ Christine A Marrese - christine.marrese@novartis.com; Jee-Hyung Lee - jeehyung.lee@novartis.com; \\ Stephen J Elliman - stephen.elliman@novartis.com; Nanguneri Nirmala - nanguneri.nirmala@novartis.com; \\ Daniel M Kemp* - daniel.kemp@novartis.com \\ * Corresponding author
}

Published: 5 June 2007

BMC Molecular Biology 2007, 8:46 doi:10.1 186/147I-2199-8-46

This article is available from: http://www.biomedcentral.com/I47|-2/99/8/46

(c) 2007 Szustakowski et al; licensee BioMed Central Ltd.

This is an Open Access article distributed under the terms of the Creative Commons Attribution License (http://creativecommons.org/licenses/by/2.0), which permits unrestricted use, distribution, and reproduction in any medium, provided the original work is properly cited.
Received: 7 August 2006

Accepted: 5 June 2007

\begin{abstract}
Background: Using a gene clustering strategy we determined intracellular pathway relationships within skeletal myotubes in response to an acute heat stress stimuli. Following heat shock, the transcriptome was analyzed by microarray in a temporal fashion to characterize the dynamic relationship of signaling pathways.

Results: Bioinformatics analyses exposed coordination of functionally-related gene sets, depicting mechanism-based responses to heat shock. Protein turnover-related pathways were significantly affected including protein folding, pre-mRNA processing, mRNA splicing, proteolysis and proteasome-related pathways. Many responses were transient, tending to normalize within 24 hours.
\end{abstract}

Conclusion: In summary, we show that the transcriptional response to acute cell stress is largely transient and proteosome-centric.

\section{Background}

Damaged skeletal muscle tissue retains the capacity to self-repair through activation, expansion and fusion of resident satellite, progenitor cells [1-3]. However, the signaling mechanisms required to trigger satellite cell activation remain unclear in this context. Emerging pathways involved in the injury-response profile of skeletal muscle include Notch [4], Akt/Foxo [5] and NFkB [6,7], which appear to play distinct roles in regeneration, hypertrophy and atrophy. Although these signaling pathways are well established, there remains a dearth of molecular detail, including the transcriptional consequence of atrophic stimuli, and this aspect forms the focus of the current study.

We hypothesized that subtle variance in gene expression may underlie significant functional events within the cell. Consistently, previous studies have addressed the transcriptional profile of recovering muscle tissue following acute injury [8]. However, such studies rely on the analysis of individual genes, which is limiting from both statistical and biological perspectives. Here, we performed a study with the tenet that mechanistic data may be more readily revealed in the context of pathway-related gene clustering 
$[9,10]$. We employed Gene Set Enrichment Analysis (GSEA), a bioinformatics approach conceived to exploit functional regulation at the pathway level. The study focused on the dynamic expression profile of acutely stressed skeletal muscle cells, and the resultant data revealed major transcriptional adjustments in a wide range of functional categories. These findings may underscore a coordinated pathway-centric response, and reveal rational strategies for target discovery in atrophic muscle diseases.

\section{Results}

In the present study, we exposed $\mathrm{C} 2 \mathrm{C} 12$ skeletal myotubes to heat shock-induced damage in order to identify coordinate patterns of transcriptional regulation. To initially authenticate this cell-based injury model, we identified several stress-related biomarkers and regulatory patterns to confirm bona fide damage response in the cells. Following heat shock treatment, cells recovered in growth medium at $37^{\circ} \mathrm{C}$, and gene expression profiles were generated at $0,1,2,4,8$ and 24 hours post-treatment. ATF3 and c-jun are critically regulated in the neuronal response to damage and during degeneration. Furthermore, these genes may play an anti-apoptotic role in the survival response of neuronal cells [11-13]. Here, both ATF3 and c-jun transcript levels were upregulated in response to heat-shock, consistent with their reported coordinate role in cell damage response (Figure 1A). A transient peak in expression of both genes occurred at 8 hours and attenuated at $24 \mathrm{~h}$ post-damage induction, indicating a regulated damage-induced response. Vimentin, an intermediate filament protein that plays a role in wound healing [14] and response to thermal stress $[15,16]$, was augmented immediately following heat shock, and peaked at 2 hours. This rapid response to cell stress was consistent with the role of vimentin in protection against cytotoxic effects (Figure 1B). Also, the membrane type 1matrix metalloproteases MMP14 and MMP2, which are functional partners during skeletal development [17] and stress response in the context of vascular injury [18], were robustly co-regulated at the transcriptional level in response to heat shock of $\mathrm{C} 2 \mathrm{C} 12$ skeletal myotubes. Their expression level rose within 2-4 hours of insult, followed by a repression of expression levels at 8 and 24 hours (Figure 1C).

Atrogin-1 is expressed specifically in skeletal and cardiac muscle, and has been shown to regulate muscle atrophy $[19,20]$. In response to heat shock, Atrogin-1 (Fbxo32) was upregulated after 8 hours, and this level of expression was maintained for at least 15 hours (Figure 1D). This dynamic profile is consistent with previous reports of
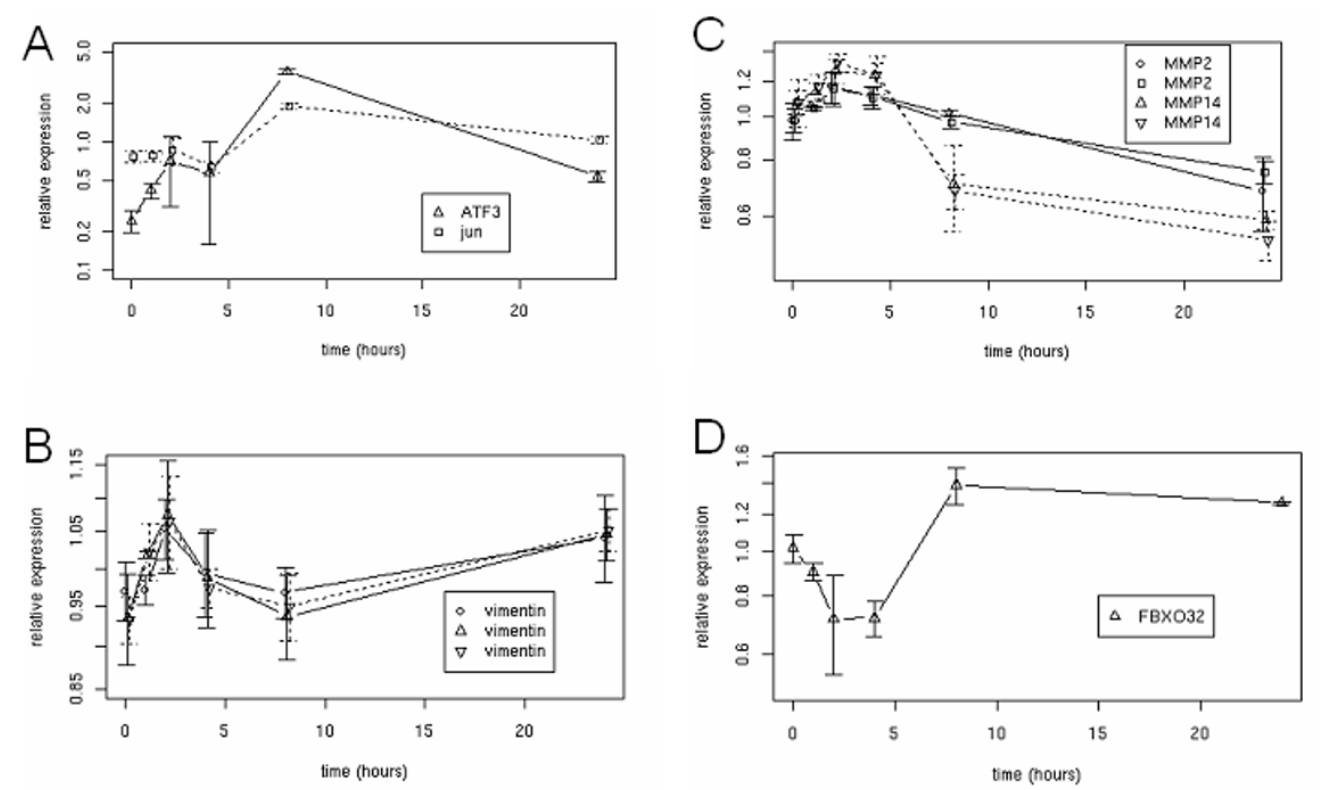

\section{Figure I}

$\mathrm{C} 2 \mathrm{Cl} 2$ cells recover from heat shock with a characteristic profile of injury response. Temporal gene expression profiles of heat shocked $\mathrm{C} 2 \mathrm{Cl} 2$ myotubes $\left(47^{\circ} \mathrm{C}\right.$ for 30 minutes). Heat shock treatment was abated at 0 hours and cells were restored to growth conditions. mRNA was isolated at I, 2, 4, 8 and 24 hours post-heat shock. (A-D) Transcriptional activity of the indicated genes was measured using Affymetrix GeneChips and data was analyzed using GeneSpring bioinformatics software. Data points represent the mean of three independent studies ( \pm S.D). (E-G) C2CI 2 cells stably expressing Foxo3a-GFP were differentiated into myotubes (E), heat shocked and recovered for 3 hours (F) or treated with $20 \mu$ M LY294002 for 3 hours (G). Cells were then viewed under fluorescent light to observe localization of the protein. 
A

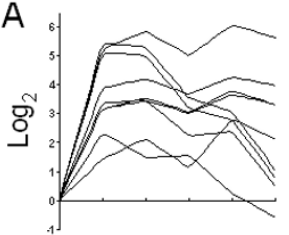

B

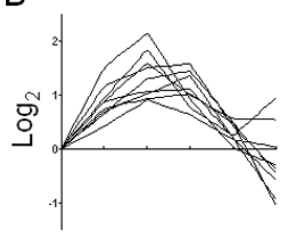

C

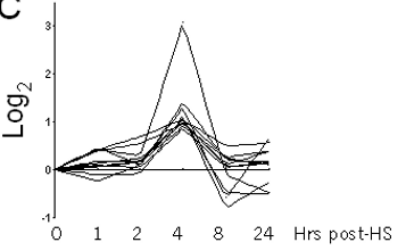

Figure 2

Temporal gene clusters during response to heat shock of $\mathrm{C} 2 \mathrm{Cl} 2$ myotubes. Temporally upregulated genes were clustered by selection of probes that coregulated with a specific peak time between I and 24 hours post-heat shock, as determined from the normalized expression profile data. Expression profiles of each gene within clusters are represented for the entire $\mathbf{2 4}$ hour timecourse to reflect the transient nature of expression.

muscle injury response, whereby the expression of atrogin-1 was concomitant with atrophy and recovery [21]. Atrogin-1 is regulated by Foxo transcription factors, via nuclear localization of Foxo in response to various stimuli that inhibit PI3K/Akt signaling and subsequently drive atrophy $[5,22]$.

\section{Transient profiles of gene expression}

Of the approximately 46,000 probes arrayed on the gene chips, the most variable and dynamically regulated were characterized by basic clustering methodology (Figure 2). The most actively regulated group of genes immediately following treatment (ie. 1 hour post heat shock) unsurprisingly comprised a number of heat-shock proteins. $h s p 1 a, h s p 1 b$ and $h s p 8$ were among the most significantly upregulated transcripts at this time point (Figure 2A). Gene sets that clustered at 2, 4, 8 and 24 hours following heat shock are displayed in Figure 2 and are partially represented in Table 1 . The 8 hour gene set was the largest group that displayed a significant upregulation, and is likely comprised of genes that were regulated downstream of immediate early genes. Therefore, this cluster may represent an important set of genes that functionally dictate the coordinated response of myogenic cells to stress or injury.

\section{Gene set enrichment analysis}

We employed a the gene set enrichment analysis strategy [10] to cluster functionally related genes in order to consider shifts in pathway activity. Individual gene sets were mined from various publicly and privately available data sources, and methodologies for the curation of functional pathways varied between sources. In all, a total of 789 gene sets made up the collection that was employed in this study, and the approach was employed to facilitate potential mechanistic insight to the myogenic cell response to injury [10]. As a control, we looked at the gene set for stress response at the 8 hour time point (Figure 3A). This probe set was significantly upregulated $\left(\mathrm{p}<1.0 \mathrm{e}^{-36}\right)$, relative to the basal expression distribution (Figure 3-3A). Furthermore, a subsidence in the stress response could be observed between 8 and 24 hours post-heat shock treatment as the gene set underwent a significant downregulation $\left(\mathrm{p}=1.4 \mathrm{e}^{-8}\right)$ that may reflect a normalization of the cell's condition (Figure 3B). These data clearly demonstrate the statistical strength of pathway analysis in the context of the heat shock response.

To gain better insight into the dynamic nature of regulated functional pathways, we traced the expression pattern of specific gene sets within the time course, such as the extracellular matrix protein-mediated signaling (EMP-M) (Figure 4 , see Additional file 1 ). The analysis revealed a pattern of regulation that reflected an initial increase in pathway activity at 1, 2, and 4 hours, followed by a timedependent decrease in expression through 8 and 24 hours post treatment. Therefore, the overall response in the EMP-M pathway to heat shock reflected an augmentation immediately following treatment, followed by a subsidence and eventual decrease in functional pathway expression after 24 hours. The transient nature of the pathway response was clearly defined with this bioinformatics approach, and is presented in Figure 4F.

A similar analysis was carried out on the BMP signaling pathway (see Additional file 1). When traced as a function of time over the 24 hour period, the BMP signaling pathway was initially decreased at 1,2 and 4 hours at the transcriptional level, and recovered through 8 and 24 hours post treatment (Figure 5). This result was consistent with the established role of BMP signaling in antagonizing myogenic specification during development, and in regenerating adult muscle tissue [23]. Furthermore, along with the stress response pathway and the EMP-M pathway expression traces, it appears that much of the initial response to heat shock was reversed within 24 hours of recovery. 
Table I: Significantly upregulated genes at specific time points following heat shock

\begin{tabular}{l}
\hline I Hours \\
HspIA \\
HspIB \\
Hsp8 \\
Cystein rich protein 6I
\end{tabular}

\section{Hours}

Procollagen, type VI, alpha 3

Procollagen, type $\mathrm{V}$, alpha I

Procollagen, type I, alpha I

Actin, beta, cytoplasmic

Ribosomal protein S24

Low density lipoprotein receptor-related protein I

Perlecan (heparan sulfate proteoglycan 2)

Myosin heavy chain IX

Early growth response I

Expressed sequence - gi:2918507

EST - gi:877253।

\author{
8 Hours \\ Hspl05 \\ Hsp40 homolog - gi: 12839599 \\ Jun oncogene \\ ATF3
}

FBJ osteosarcoma oncogene

Bcl2-associated athanogene 3

Developmentally and sexually retarded with transient immune abnormalities Endothelin I

Placental growth factor

Solute carrier family 19 (thiamine transproter), member 2

AXINI up-regulated I

Moderate similarity to protein ref:NP_004410.2 (H.sapiens) phosphatase

Heme oxygenase (decycling) I

Growth arrest and DNA-damage-inducible 45 gamma

Myeloid differentiation primary response gene 116

$\mathrm{v}$-maf musculoaponeurotic fibrosarcoma oncogene family, protein $\mathrm{F}$ (avian)

Dual specificity phosphatase 2

Diphtheria toxin receptor

Transformed mouse 3T3 cell double minute 2

Interferon-related developmental regulator I

Activity regulated cytoskeletal-associated protein

mRNA - gi: 16877863

Dnal (Hsp40) homolog, subfamily A, member 4
Analysis of the most active gene sets through the entirety of the time-course revealed a notable phenomenon, typified by the dynamic profile of the protein biosynthesis pathway gene set. In response to heat shock treatment, the genes in this pathway underwent a significant and immediate upregulation, which gradually declined over the next 24 hours (Figure 6). The trend for this particular functional pathway suggested that protein turnover was highly regulated in the response to heat shock-induced stress, and this hypothesis was further supported by the apparent upregulation of several related pathways involved in the expression and degradation of proteins.

After 8 hours recovery from heat shock, a selection of gene sets related to core gene expression machinery and protein turnover, were significantly upregulated (Table 2). This general increase in protein metabolism pathways as an immediate response to injury may reflect the clearance and replacement (turnover) of the protein complement of the cell.

\section{Discussion and Conclusion}

This study was conducted to explore changes in gene expression following acute injury of $\mathrm{C} 2 \mathrm{C} 12$ myotubes, and to reveal regulation of pathways during initial recovery. 866 individual transcripts represented on the microarray varied more than 2 fold over the course of the study, and the data revealed significant transcriptional changes in a wide variety of functional classes following heat shock damage to the cells. We devised the current study with two distinct dimensions. Firstly, to trace the timecourse of recovery over a 24 hour period, and secondly, to analyze in a pathway-centric manner in order to extract hypotheses of coordinated molecular mechanisms that 

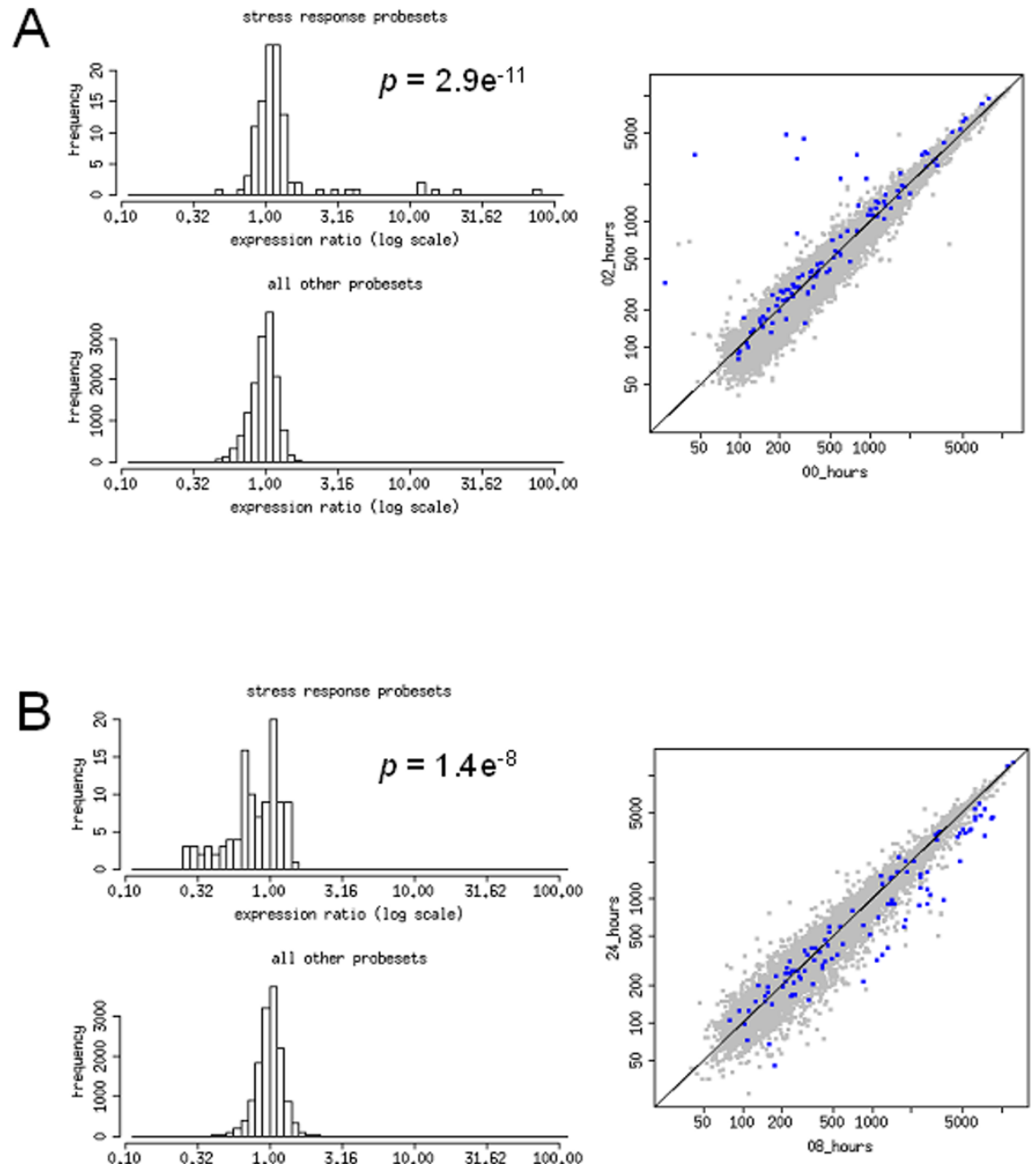

Figure 3

Stress response gene set is bi-directional during response to heat shock in $\mathrm{C} 2 \mathrm{CI} 2$ cell. Distribution in stress response-related gene sets during response to heat shock of $\mathrm{C} 2 \mathrm{Cl} 2$ myotubes. All probes representing the stress response gene set are presented as an expression ratio of time $a$ against time $b$. Frequency (y-axis) represents the number of probes in each gene set with the corresponding expression ratio ( $x$-axis). The statistical significance of the mean expression variance ratio for the gene set relative to all other probesets is indicated. Variance between $0-8$ hours (A) and $8-24$ hours (B) post-heat shock are depicted in the figure. Dotplot representations of GSEA as a function of $C 2 \mathrm{C} 12$ response to heat shock is also presented. The $x$-axis of each plot represents expression levels at time $a$, and the $y$-axis represents expression at time $b$. Each dot represents a single probe on the GeneChip. The total probe set (grey dots) and the specific gene set (blue dots) are presented on the same plot to give direct perspective of gene set regulation. The stress response probe set is represented by 122 gene probes, previously annotated as related to the stress response. The list is attached in Additional file I.

occur during cellular stress and recovery. Two notable pathways significantly modulated during recovery were the BMP signaling pathway, and the extracellular matrixprotein mediated signaling pathway, both of which are known to function in myogenesis, either by directing lineage specification (BMP) or structural/regenerative signaling (ECM-M). Additionally, the muscle-specific E3 ligase gene, Atrogin-1 was upregulated significantly, consistent with its reported role in mediating muscle atrophy in response to catabolic signals [19], and this in turn was coincident with our observation of nuclear translocation of Foxo3a following heat shock $[5,22]$. This reconstruction of a well documented atrophic pathway served to validate the heat shock treatment paradigm as a useful model of acute muscle stress.

The experimental approach carried out in this study demonstrated the value of characterizing cellular responses in 

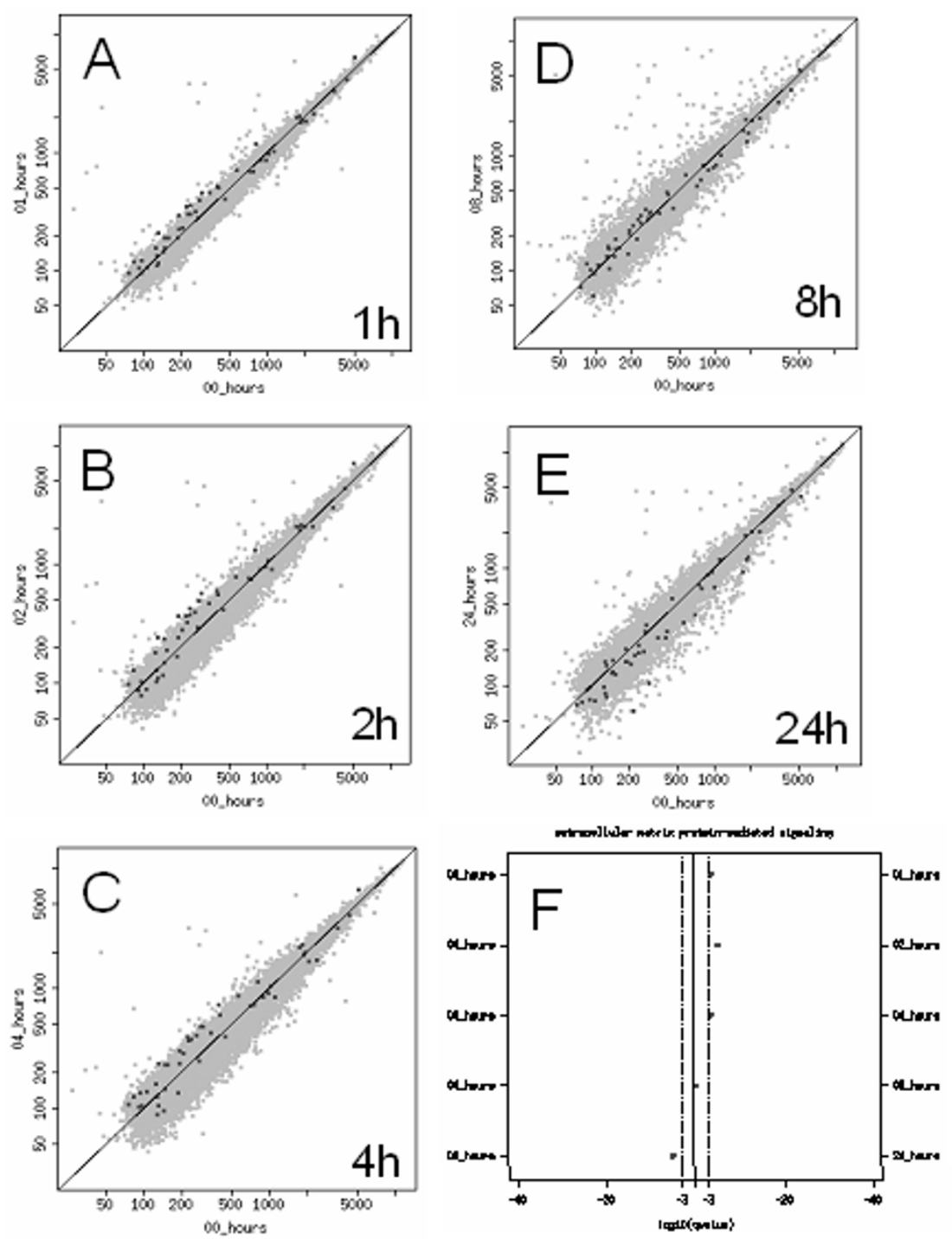

\section{Figure 4}

Dynamic regulation of the EMP-M gene set following heat shock. (A-E) Dotplot diagrams represent the temporal shift in mean expression levels of the EMP-M pathway gene set, relative to the 0 hour time point. (F), an overview of the dynamic pattern of mean expression levels of the EMP-M pathway gene set. Shifts to the right or left of the vertical center line represent statistical significance of directed shift ( $q$ value), rather than the mean expression level per se. The list of genes/probes that constitute the EMP-M pathway gene set can be found in Additional file I.

a temporal fashion, as transcriptional regulation was commonly found to be non-static between contiguous time points within the first 24 hours of treatment, and often presented transient regulation that required a time-course dimension to clarify.

A notable trend that emerged from the data was an apparent increase in protein turnover apparatus-related gene sets. The most significantly upregulated gene sets included those for both transcriptional activity, translational activity and protein modification, as well as the proteolysis and proteosome pathways. This suggests that a primary response of skeletal myotubes to heat shock treatment is to renew the protein complement of the cell, presumably as a defense mechanism against proteomic damage, and potential aberrant consequences in the function or integrity of the cell. The data also show that much of this response is transient, and appears to normalize within 24 hours of the acute insult at the transcriptional level.

In summary, the data presented in this report demonstrate a dynamic resolution of gene expression in response to 

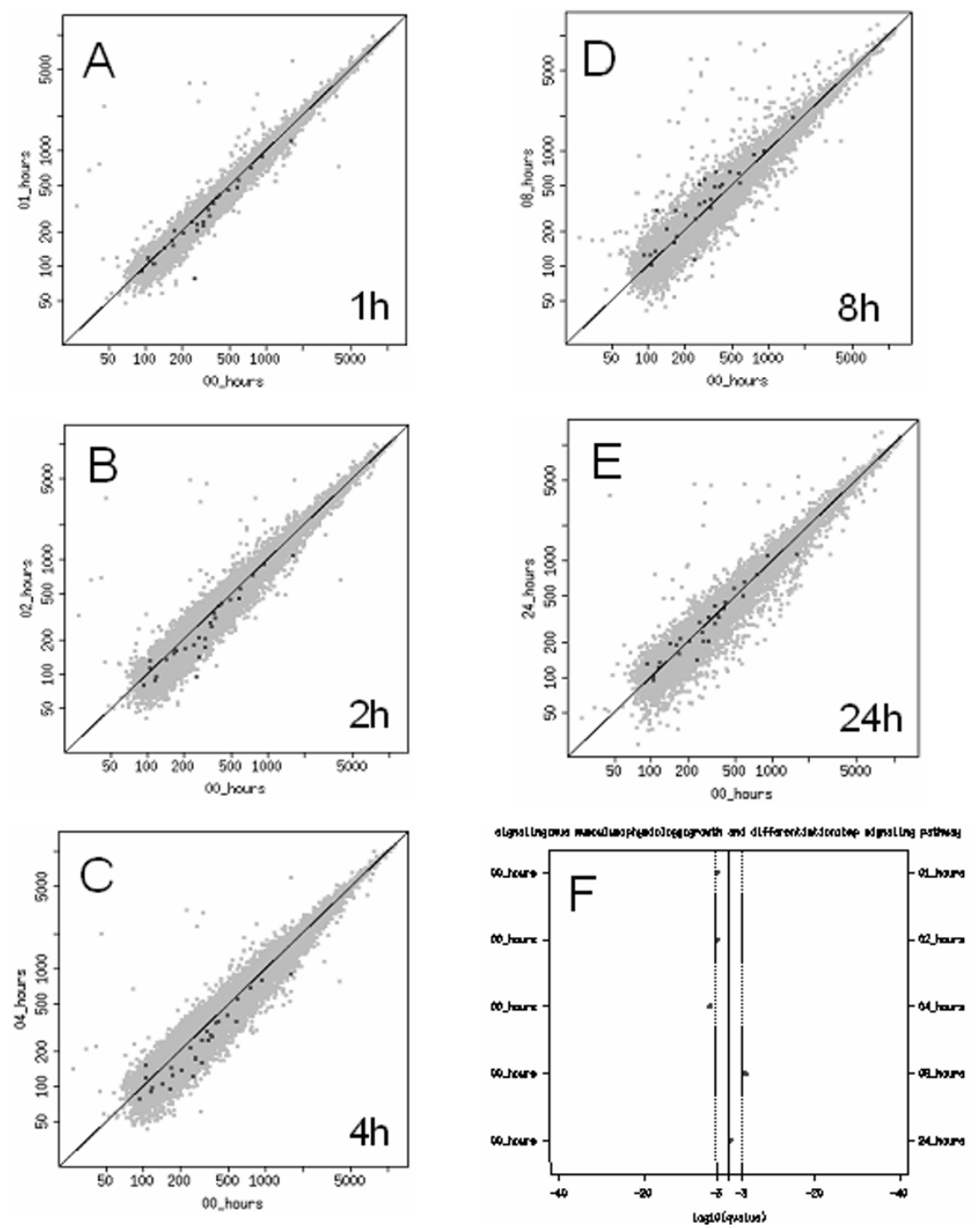

\section{Figure 5}

Dynamic regulation of the BMP gene set following heat shock. (A-E) Dotplot diagrams represent the temporal shift in mean expression levels of the BMP pathway gene set, relative to the 0 hour time point. $(F)$, an overview of the dynamic pattern of mean expression levels of the BMP pathway gene set. Shifts to the right or left of the vertical center line represent statistical significance of directed shift ( $q$ value), rather than the mean expression level per se. The list of genes/probes that constitute the BMP pathway gene set can be found in Additional file I.

acute stress that implicates waves of pathway activity in the cell's metabolic recovery. Further validation of these data are required, however, in order to demonstrate clearly the practical nature of these pathways as part of the functional stress response profile.

\section{Methods}

\section{Cell culture and treatment}

C2C12 mouse skeletal myoblasts were cultured in DMEM high glucose with $10 \%$ FBS and 1\% penicillin/streptomycin (Gibco), and maintained at $37^{\circ} \mathrm{C}$ and $5 \% \mathrm{CO}_{2}$. Cells were grown to confluence and then differentiated for seven days in media containing 3\% fetal bovine serum.
Cells were heat shocked at $47^{\circ} \mathrm{C}$ for 30 minutes, and returned to the incubator at $37^{\circ} \mathrm{C}$. After heat shock, cells were harvested at 1, 2, 4, 8, and 24 hours and processed to isolate the RNA using the RNeasy kit (Qiagen). Myotubes were isolated for expression profiling by serially exposing the culture to increasing concentrations of trypsin. This allowed for the multinucleated myotubes to become detached from the plate, while the mononucleate myoblasts remained adherent. This process ensured that we were profiling differentiated skeletal myotubes only, without contamination of myoblasts. $20 \mu \mathrm{g}$ RNA per sample was microarrayed using the Mouse Affymetrix MOE430 Plus 2.0 chip. The heat-shock treatment conditions were 

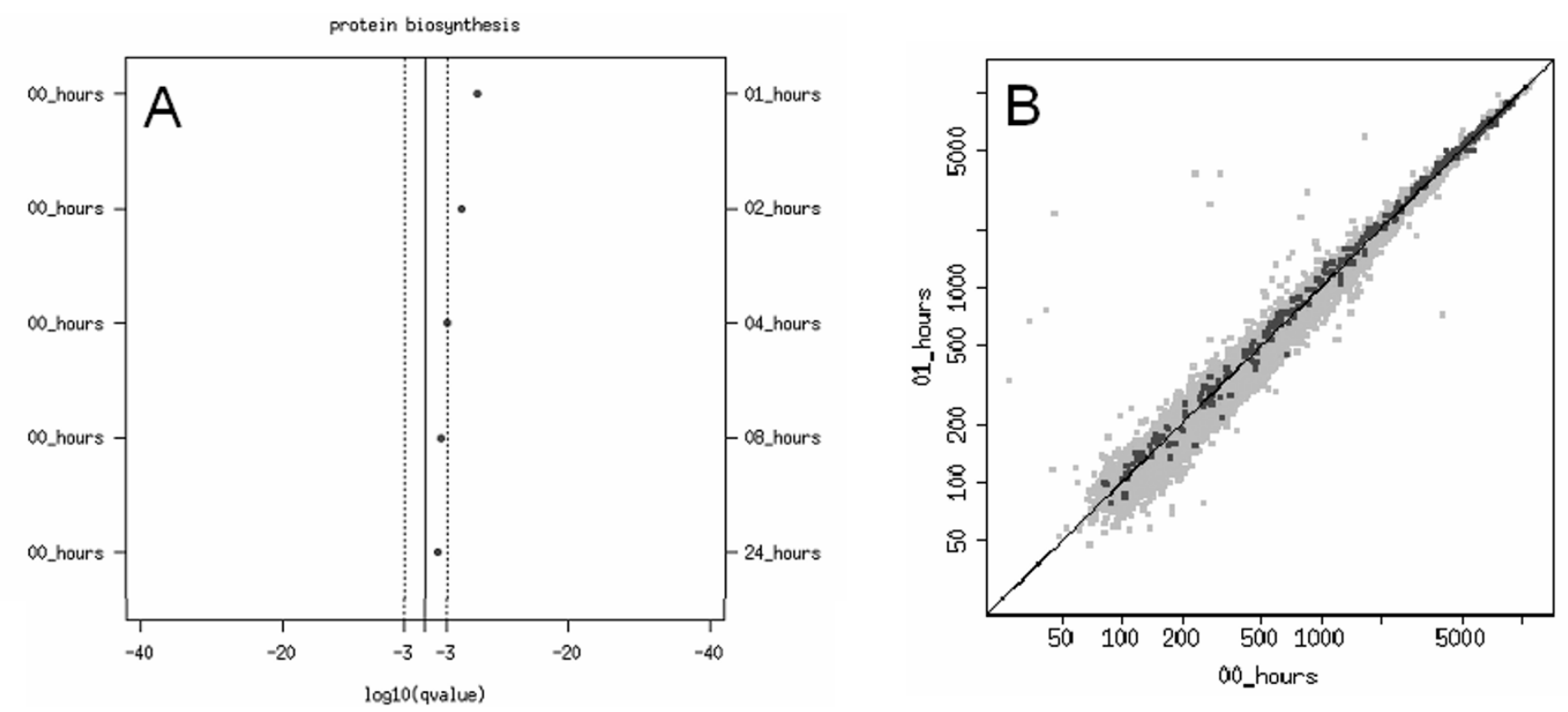

Figure 6

Dynamic response of the protein biosynthesis pathway following heat shock. (A) Overview depiction of the dynamic response of the protein biosynthesis pathway gene set following heat shock over 24 hours. Data is represented as for Figure 5 . (B) Dotplot diagram showing the upregulation in expression of the same gene set after I hour post-heat shock.

determined not to be cytotoxic, as continued culture in normal growth conditions was sufficient for full recovery of the cells (data not shown).

\section{Bioinformatics}

Raw intensity files were imported into GeneSpring ${ }^{\circledR}$ v.6.2 (Silicon Genetics, US) and filtered such that genes with a raw expression level of less than 100 were excluded from any future analyses. The resulting gene list was filtered to identify genes with a fold change increase or decrease of 2 or greater. Statistically significant genes were found using one-way ANOVA with time as variable and no multiple testing correction.

Table 2: Most significantly upregulated gene sets at 8 hours post heat shock

\begin{tabular}{|c|c|c|c|}
\hline Functional Pathway & $\begin{array}{c}\text { No. of } \\
\text { probes in set }\end{array}$ & $p$-value & $q$-value \\
\hline $\begin{array}{l}\text { Protein metabolism and } \\
\text { modification }\end{array}$ & 1794 & $<\mid e^{-3 \mid}$ & $<\mid e^{-3 \mid}$ \\
\hline Protein folding & 173 & $1.1 \mathrm{e}^{-13}$ & $1.8 e^{-11}$ \\
\hline Nuclear transport & 87 & $8.4 e^{-8}$ & $7.9 e^{-6}$ \\
\hline Pre-mRNA processing & 209 & $4.0 e^{-7}$ & $2.1 e^{-5}$ \\
\hline Proteolysis & 461 & $1.7 \mathrm{e}^{-6}$ & $6.2 e^{-5}$ \\
\hline mRNA transcription regulation & 676 & $9.1 \mathrm{e}^{-7}$ & $4.2 e^{-5}$ \\
\hline Protein complex assembly & 53 & $1.2 \mathrm{e}^{-6}$ & $4.8 e^{-5}$ \\
\hline mRNA splicing & 156 & $7.5 e^{-6}$ & $2.0 \mathrm{e}^{-4}$ \\
\hline Proteasome & 37 & $1.3 \mathrm{e}^{-4}$ & $1.9 \mathrm{e}^{-3}$ \\
\hline
\end{tabular}

An in-house implementation of the Gene Set Enrichment Analysis method [10] was used to analyze microarray data. As input, GSEA requires microarray data from two conditions to be compared (e.g. myoblasts vs myotubes). Genes with expression levels below 100 on more than $75 \%$ of the Genechips were discarded. Then, the relative expression level under condition ${ }_{1}$ and condition $_{2}$ was computed as an expression ratio $r_{i}$

$$
r_{i}=\frac{\mu_{i, 1}}{\mu_{i, 2}}
$$

where $\mu_{i, j}$ is the average expression value for gene $i$ under condition $_{j}$. Genes were then sorted according to their expression ratios. Next, the collection of available gene sets were projected onto the sorted gene list. In essence, this step applies a priori biological knowledge to the experimental data to identify functionally related genes that are expressed in a coordinated fashion. Gene sets were processed individually and used to partition the genes into two groups: those gene in a pathway, and all other genes measured on the Genechip. A two-tailed Wilcoxon ranksum test was then calculated to determine if the genes in each gene set were enriched at either the top or bottom of the sorted list. The Wilcoxon p-values were then transformed into false discovery rate q-values $[24,25]$ as a means of multiple hypothesis testing correction. 


\section{Authors' contributions}

JDS developed the bioinformatics algorithms and analysis. PAK designed and performed the heat shock experiment. CAM performed statistical analysis. JHL and SJE participated in the design and coordination of the study. NRN and DMK conceived of the study and drafted the manuscript. All authors read and approved the final manuscript.

\section{Additional material}

\section{Additional File 1}

Heat Shock supplementary probe lists. Table of genes that form the extracellular matrix protein-mediated signaling probe set, and the heat shock probe set, respectively.

Click here for file

[http://www.biomedcentral.com/content/supplementary/1471-

2199-8-46-S1.xls]

\section{Acknowledgements}

We thank Qicheng Ma for help in the development of GSEA.

\section{References}

I. Charge SB, Rudnicki MA: Cellular and molecular regulation of muscle regeneration. Physiol Rev 2004, 84:209-238.

2. Sherwood RI, Christensen JL, Conboy IM, Conboy MJ, Rando TA, Weissman IL, Wagers AJ: Isolation of adult mouse myogenic progenitors: functional heterogeneity of cells within and engrafting skeletal muscle. Cell 2004, I 1 9:543-554.

3. Collins CA, Olsen I, Zammit PS, Heslop L, Petrie A, Partridge TA, Morgan JE: Stem cell function, self-renewal, and behavioral heterogeneity of cells from the adult muscle satellite cell niche. Cell 2005, I 22:289-30I.

4. Conboy IM, Rando TA: Aging, stem cells and tissue regeneration: lessons from muscle. Cell Cycle 2005, 4:407-4IO.

5. Stitt TN, Drujan D, Clarke BA, Panaro F, Timofeyva Y, Kline WO, Gonzalez M, Yancopoulos GD, Glass DJ: The IGF-I/PI3K/Akt pathway prevents expression of muscle atrophy-induced ubiquitin ligases by inhibiting FOXO transcription factors. Mol Cell 2004, 1 4:395-403.

6. Hunter RB, Kandarian SC: Disruption of either the Nfkb I or the Bcl3 gene inhibits skeletal muscle atrophy. I Clin Invest 2004, I 14:|504-1511.

7. Cai D, Frantz JD, Tawa NE Jr., Melendez PA, Oh BC, Lidov HG, Hasselgren PO, Frontera WR, Lee J, Glass DJ, Shoelson SE: IKKbeta/NFkappaB activation causes severe muscle wasting in mice. Cell 2004, I I 9:285-298.

8. Zhao P, Hoffman EP: Embryonic myogenesis pathways in muscle regeneration. Dev Dyn 2004, 229:380-392.

9. Patti ME, Butte Al, Crunkhorn S, Cusi K, Berria R, Kashyap S, Miyazaki Y, Kohane I, Costello M, Saccone R, Landaker EJ, Goldfine AB, Mun E, DeFronzo R, Finlayson J, Kahn CR, Mandarino LJ: Coordinated reduction of genes of oxidative metabolism in humans with insulin resistance and diabetes: Potential role of $\mathrm{PGCI}$ and NRFI. Proc Natl Acad Sci U S A 2003, 100:8466-847I.

10. Mootha VK, Lindgren CM, Eriksson KF, Subramanian A, Sihag S, Lehar J. Puigserver P, Carlsson E, Ridderstrale M, Laurila E, Houstis N, Daly M], Patterson N, Mesirov JP, Golub TR, Tamayo P, Spiegelman B, Lander ES, Hirschhorn JN, Altshuler D, Groop LC: PGC-Ialpharesponsive genes involved in oxidative phosphorylation are coordinately downregulated in human diabetes. Nat Genet 2003, 34:267-273.

II. Mason MR, Lieberman AR, Anderson PN: Corticospinal neurons up-regulate a range of growth-associated genes following intracortical, but not spinal, axotomy. Eur J Neurosci 2003, 18:789-802.

12. Tsujino H, Kondo E, Fukuoka T, Dai Y, Tokunaga A, Miki K, Yonenobu K, Ochi T, Noguchi K: Activating transcription factor 3 (ATF3) induction by axotomy in sensory and motoneurons: A novel neuronal marker of nerve injury. Mol Cell Neurosci 2000, 15:170-182.

13. Nakagomi S, Suzuki Y, Namikawa K, Kiryu-Seo S, Kiyama H: Expression of the activating transcription factor 3 prevents c-Jun $\mathbf{N}$. terminal kinase-induced neuronal death by promoting heat shock protein 27 expression and Akt activation. I Neurosci 2003, 23:5187-5196.

14. SehI PD, Tai JT, Hillan KJ, Brown LA, Goddard A, Yang R, Jin H, Lowe DG: Application of cDNA microarrays in determining molecular phenotype in cardiac growth, development, and response to injury. Circulation 2000, 101:1990-1999.

15. Muchowski PJ, Valdez MM, Clark Jl: AlphaB-crystallin selectively targets intermediate filament proteins during thermal stress. Invest Ophthalmol Vis Sci 1999, 40:95I-958.

16. Vilaboa NE, Garcia-Bermejo L, Perez C, de Blas E, Calle C, Aller P: Heat-shock and cadmium chloride increase the vimentin mRNA and protein levels in U-937 human promonocytic cells. J Cell Sci 1997, 110 ( Pt 2):201-207.

17. Oblander SA, Zhou Z, Galvez BG, Starcher B, Shannon JM, Durbeej M, Arroyo AG, Tryggvason K, Apte SS: Distinctive functions of membrane type I matrix-metalloprotease (MTI-MMP or MMP. $14)$ in lung and submandibular gland development are independent of its role in pro-MMP-2 activation. Dev Biol 2005, 277:255-269.

18. Zahradka P, Harding G, Litchie B, Thomas S, Werner JP, Wilson DP, Yurkova N: Activation of MMP-2 in response to vascular injury is mediated by phosphatidylinositol 3-kinase-dependent expression of MTI-MMP. Am J Physiol Heart Circ Physiol 2004, 287: $\mathrm{H} 286 \mathrm{I}-70$.

19. Bodine SC, Latres E, Baumhueter S, Lai VK, Nunez L, Clarke BA, Poueymirou WT, Panaro Fl, Na E, Dharmarajan K, Pan ZQ, Valenzuela DM, DeChiara TM, Stitt TN, Yancopoulos GD, Glass DJ: Identification of ubiquitin ligases required for skeletal muscle atrophy. Science 200I, 294: I704-I708.

20. Gomes MD, Lecker SH, Jagoe RT, Navon A, Goldberg AL: AtroginI, a muscle-specific F-box protein highly expressed during muscle atrophy. Proc Natl Acad Sci U S A 200I, 98: I4440-I 4445

21. Sandri M, Sandri C, Gilbert A, Skurk C, Calabria E, Picard A, Walsh K, Schiaffino S, Lecker SH, Goldberg AL: Foxo transcription factors induce the atrophy-related ubiquitin ligase atrogin-I and cause skeletal muscle atrophy. Cell 2004, I 17:399-4I2.

22. Kamei Y, Miura S, Suzuki M, Kai Y, Mizukami J, Taniguchi T, Mochida K, Hata T, Matsuda J, Aburatani H, Nishino I, Ezaki O: Skeletal muscle FOXOI (FKHR) transgenic mice have less skeletal muscle mass, down-regulated Type I (slow twitch/red muscle) fiber genes, and impaired glycemic control. J Biol Chem 2004, 279:4 || |4-4||23

23. Katagiri T, Imada M, Yanai T, Suda T, Takahashi N, Kamijo R: Identification of a BMP-responsive element in Id I, the gene for inhibition of myogenesis. Genes Cells 2002, 7:949-960.

24. Storey JD, Tibshirani R: Statistical methods for identifying differentially expressed genes in DNA microarrays. Methods Mol Biol 2003, 224:149-157.

25. Storey JD, Tibshirani R: Statistical significance for genomewide studies. Proc Natl Acad Sci U S A 2003, 100:9440-9445.

Publish with Bio Med Central and every scientist can read your work free of charge

"BioMed Central will be the most significant development for disseminating the results of biomedical research in our lifetime. "

Sir Paul Nurse, Cancer Research UK

Your research papers will be:

- available free of charge to the entire biomedical community

- peer reviewed and published immediately upon acceptance

- cited in PubMed and archived on PubMed Central

- yours - you keep the copyright
BioMedcentral 